05;09

\title{
Деградация и разрушение тонких стальных пленок при многократном воздействии сверхкоротких импульсов THz-излучения
}

\author{
(c) О.В. Чефонов ${ }^{1}$, А.В. Овчинников ${ }^{1, \uparrow, ~ С . А . ~ Е в л а ш и н ~}{ }^{2}$, М.Б. Агранат ${ }^{1}$ \\ ${ }^{1}$ Объединенный институт высоких температур РАН, Москва, Россия \\ ${ }^{2}$ Центр дизайна, производства и материалов, Сколковский институт науки и технологий, Москва, Россия \\ ๑E-mail: ovtch2006@yandex.ru
}

Поступило в Редакцию 7 марта 2019 г.

В окончательной редакции 7 марта 2019 г.

Принято к публикации 19 марта 2019 г.

\begin{abstract}
Проведены исследования разрушения тонких пленок из нержавеющей стали при многократном воздействии сверхкоротких импульсов направленного терагерцевого излучения. Терагерцевый импульс длительностью в единицы пикосекунд по сути моделирует нерезонансное воздействие на объект квазипостоянного электрического поля с высокой напряженностью (до $20 \mathrm{MV} / \mathrm{cm}$ ).
\end{abstract}

Ключевые слова: терагерцевое излучение, тонкая пленка металла, разрушение, сверхкороткий импульс.

DOI: 10.21883/PJTF.2019.11.47824.17775

Развитие нанотехнологий стимулирует развитие методов исследования тонких (нанометровых размеров) пленок и пленочных покрытий. Такие пленки широко используются в микроэлектронике, нанофотонике, вычислительной технике и промышленности, оптике и оптоэлектронике, космической и бытовой промышленности, в разнообразных технических отраслях. Особое внимание уделяется в силу специфичности их свойств проводящим металлическим пленкам [1-4]. В связи с развитием в последнее время источников сильных электромагнитных полей в терагерцевом (THz) и СВЧ-диапазонах спектра излучения становится актуальным проведение исследований силового (разрушительного) воздействия электрических полей с напряженностью 1-100 MV/cm на пленки металлов, полупроводников и диэлектриков.

Настоящая работа посвящена экспериментальным исследованиям деградации и разрушения тонких пленок из нержавеющей стали марки AISI 321 при многократном воздействии сверхкоротких импульсов THz-излучения с напряженностью электрического поля до $20 \mathrm{MV} / \mathrm{cm}$. Ранее подобные исследования проводились нами на пленках алюминия [5] и никеля [6].

В экспериментах использовалась тераваттная фемтосекундная хром-форстеритовая лазерная система с энергией импульсов до $80 \mathrm{~mJ}$, длительностью $80 \mathrm{fs}$, длиной волны излучения $1240 \mathrm{~nm}$ и частотой повторения $10 \mathrm{~Hz}$. С помощью нелинейных органических кристаллов методом оптического выпрямления осуществлялось спектральное преобразование излучения ближнего инфракрасного диапазона в излучение дальнего инфракрасного (терагерцевого) диапазона. На выходе терагерцевого преобразователя генерировалось когерентное (по пространству) направленное излучение. Такой источник в ряде работ называют терагерцевым ,лазером“.
Эффективная генерация терагерцевого излучения с помощью фемтосекундной хром-форстеритовой лазерной системы была впервые продемонстрирована в кристаллах DSTMS, DAST и OH1 [7]. Были получены сверхкороткие (одно- и двухпериодные) импульсы терагерцевого излучения с рекордной напряженностью электрического поля $42 \mathrm{MV} / \mathrm{cm}$. Параметры хром-форстеритовой лазерной системы позволяют благодаря высокой эффективности преобразования получить ТHz-импульсы с напряженностью электрического поля до $100 \mathrm{MV} / \mathrm{cm}$ (при наличии кристаллов-преобразователей больших размеров).

Для преобразования оптического излучения в терагерцевое использовался нелинейный кристалл DSTMS. Параметры излучения, оптическая схема и методика измерений подробно описаны в $[5,6]$.

Для определения плотности энергии терагерцевого излучения на поверхности исследуемого образца с помощью калиброванной ячейки Голея измерялась энергия THz-импульса, а размер пятна измерялся „ножевым“ методом. Максимальная плотность энергии в экспериментах достигала $350 \pm 20 \mathrm{~mJ} / \mathrm{cm}^{2}$ при энергии в импульсе $100 \pm 5 \mu \mathrm{J}$ и диаметре пучка $180 \mu \mathrm{m}$ на уровне $1 / e$. Измерения напряженности электрического поля THz-импульса в фокальной плоскости параболического зеркала осуществлялись методом электрооптического детектирования, и в максимуме она достигала $18 \mathrm{MV} / \mathrm{cm}$. Временна́я форма импульса и его спектр представлены на рис. 1.

Измерения проводились с мишенью из стали AISI 321. Мишень изготовлена в виде тонкой пленки стали толщиной $20 \mathrm{~nm}$, напыленной на стеклянную подложку толщиной $180 \mu \mathrm{m}$.

Разрушение пленки было обнаружено при многократном воздействии THz-импульса с высокой напряженностью электрического поля. Многократное воздействие 

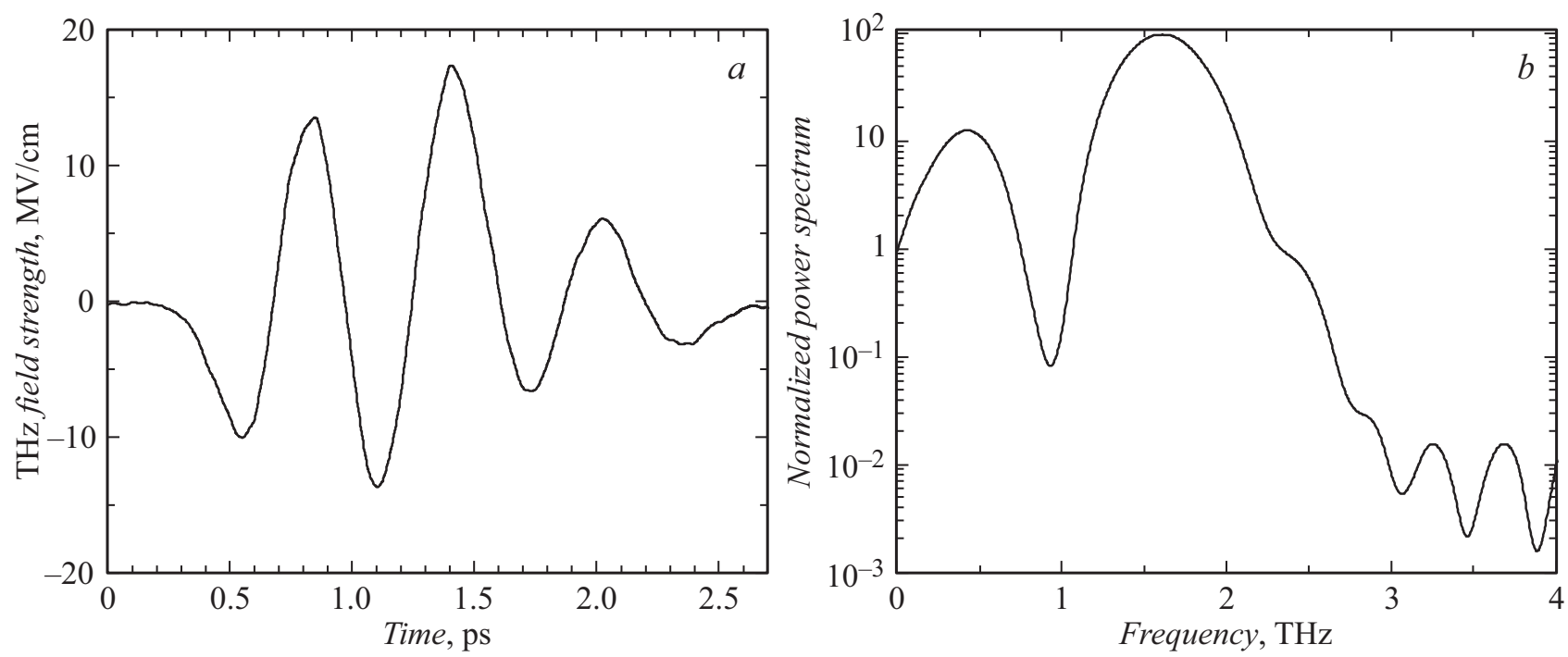

Рис. 1. Временна́я форма $(a)$ и спектр $(b)$ терагерцевого импульса при максимальной плотности энергии $350 \pm 20 \mathrm{~mJ} / \mathrm{cm}^{2}$.

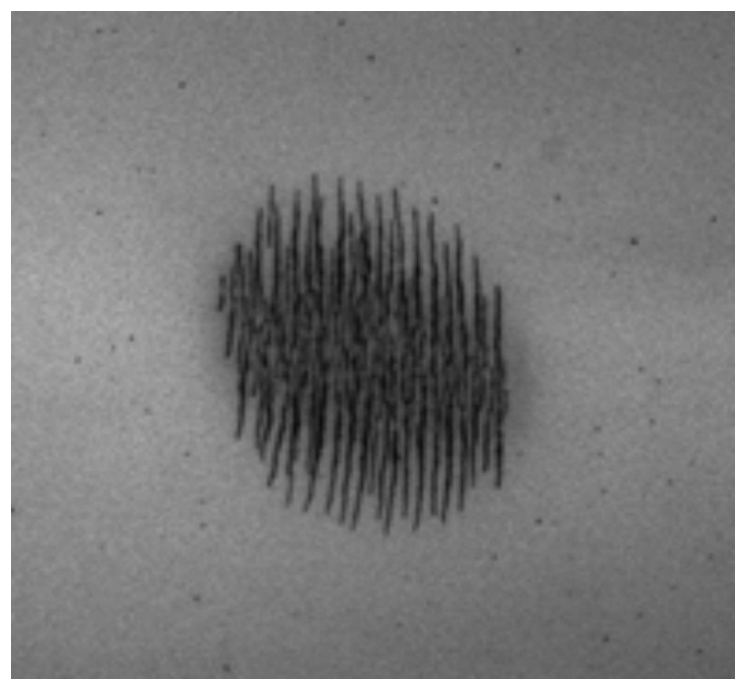

Pис. 2. Изображение характерных повреждений пленки, полученное с помощью оптического микроскопа (направление вектора напряженности электрического поля перпендикулярно направлению роста трещины).

осуществлялось последовательностью из 300 импульсов с периодом следования $100 \mathrm{~ms}$. На рис. 2, 3 представлены изображения характерных повреждений пленки стали при воздействии THz-импульсов, полученные с помощью оптического и сканирующего электронного микроскопа с различным увеличением.

Разрушения формируются в виде вытянутых каналов нарушения сплошности металлической пленки, ориентированных перпендикулярно вектору напряженности электрического поля THz-излучения. Длина каналов растет с ростом числа импульсов $N$, а ширина уменьшается по мере удаления от центра к периферии пятна.
Максимальная ширина каналов в центральной части области воздействия достигает $\sim 1 \mu \mathrm{m}$ и уменьшается до субмикронного размера на периферии. Ранее аналогичный характер разрушения наблюдался на пленках алюминия [5] и никеля $[6,8]$.

Пороговое значение плотности энергии определялось по отсутствию повреждений на поверхности пленки и составило величину $250 \pm 20 \mathrm{~mJ} / \mathrm{cm}^{2}$.

Качественно процесс разрушения можно представить в следующем виде. THz-импульс в центре пятна фокусировки (в области максимальной напряженности поля) инициирует создание микротрещины путем образования механических напряжений. Можно предположить, что в дальнейшем при многократном облучении в каждом следующем импульсе происходит усиление поля в области микротрещины. Это приводит к росту микротрещины в продольном направлении перпендикулярно вектору напряженности электрического поля и увеличению толщины в поперечном направлении. Рост микротрещин сопровождается абляцией пленки в микрообластях (подобно механизму однократного разрушения $[5,9])$.

Наибольший интерес, по мнению авторов, представляет механизм инициирования процесса образования микротрещин. Мы считаем, что он основан на ранее ненаблюдавшемся явлении электрострикции в тонких металлических пленках.

О возможности объяснения с помощью электрострикции образования поверхностных периодических структур при воздействии фемтосекундных лазерных импульсов с возбуждением поверхностных электромагнитных волн сообщалось в [10]. Однако мы считаем, что при воздействии THz-импульсов проявление механизма электрострикции носит принципиально другой характер, изложенный в нашей работе [5].

С помощью источника терагерцевого излучения пикосекундной длительности смоделировано сверхкороткое 

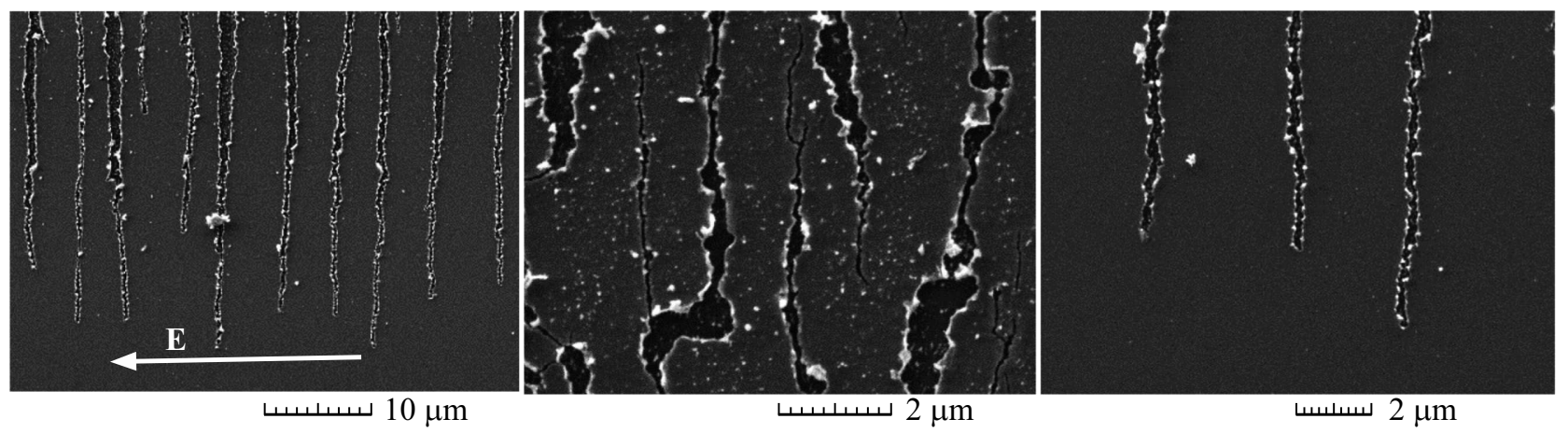

Рис. 3. Изображения (в разных масштабах) характерных повреждений пленки, полученные с помощью электронного микроскопа.

по длительности квазипостоянное электрическое поле с максимальной напряженностью $18 \mathrm{MV} / \mathrm{cm}$. Было проведено высокоскоростное деформирование и разрушение тонкой пленки стали AISI 321. Пороговое значение плотности энергии определялось по отсутствию повреждений на поверхности пленки и составило величину $250 \pm 20 \mathrm{~mJ} / \mathrm{cm}^{2}$. Предполагается, что механизмом инициирования разрушения пленки толщиной менее скинслоя для THz-частот излучения является электрострикция.

Таким образом, в работе проведены экспериментальные исследования стойкости тонких стальных пленок к воздействию сверхкоротких двухпериодных импульсов терагерцевого излучения с высокой напряженностью электрического поля.

\section{Благодарности}

Экспериментальные работы выполнены на уникальной установке „Лазерный тераваттный фемтосекундный комплекс“, входящей в состав ЦКП „Лазерный фемтосекундный комплекс“ ОИВТ РАН.

\section{Конфликт интересов}

Авторы заявляют, что у них нет конфликта интересов.

\section{Список литературы}

[1] Бондаренко П.Н., Емельянов О.А. // Письма в ЖТФ. 2005. T. 31. B. 14. C. 67-72.

[2] Емельянов О.А. // ЖТФ. 2008. Т. 78. В. 7. С. 48-56.

[3] Шугуров А.Р., Панин А.В. // Физ. мезомеханика. 2009. T. 12. № 3. C. 23-32.

[4] Kudryashov S.I., Gakovic B., Danilov P.A., Petrovic S.M., Milovanovic D., Rudenko A.A., Ionin A.A. // Appl. Phys. Lett. 2018. V. 112. N 2. P. 023103. DOI: $10.1063 / 1.5010793$

[5] Agranat M.B., Chefonov O.V., Ovchinnikov A.V., Ashitkov S.I., Fortov V.E., Kondratenko P.S. // Phys. Rev. Lett. 2018. V. 120. N 8. P. 085704 (1-5). DOI: 10.1103/PhysRevLett.120.085704

[6] Chefonov O.V., Ovchinnikov A.V., Evlashin S.A., Agranat M.B. // Millimeter Terahertz Waves. 2018. V. 39. N 11. P. $1047-1054$. DOI: $10.1007 / \mathrm{s} 10762-018-0537-8$
[7] Vicario C., Jazbinsek M., Ovchinnikov A.V., Chefonov O.V., Ashitkov S.I., Agranat M.B., Hauri C.P. // Opt. Express. 2015. V. 23. N 4. P. 4573-4580. DOI: 10.1364/OE.23.004573

[8] Shalaby M., Vicario C., Hauri C.P. // Appl. Phys. Lett. 2016. V. 108. N 18. P. 182903. DOI: $10.1063 / 1.4948472$

[9] Bezhanov S.G., Uryupin S.A. // Opt. Lett. 2018. V. 43. N 13. P. 3069-3072. DOI: 10.1364/OL.43.003069

[10] Pavlyniuk O.R., Datsyuk V.V. // Nanoscale Res. Lett. 2016. V. 11. N 1. P. 16 (1-6). DOI: 10.1186/s11671-015-1224-5 